\title{
Exploring Diversified Performance Indicators for Evaluating Non- Urbanized Transit Program Outcomes
}

\author{
Eunice V. Akoto, Ph.D. \\ Henderson State University
}

\begin{abstract}
Non-urbanized (rural) transit goals include the ability to use available government funds to provide adequate and efficient transportation services while increasing mobility and accessibility. However, outcomes of these goals cannot be examined exclusively with the "traditional" transit performance indicators that are more conducive to urban systems. This study explores diversified indicators-namely, efficiency, effectiveness, and mobility constructs for evaluating program outcomes of non-urbanized transit systems-using Mississippi's Section 5311 program as the case. The study examined how Section 5311 providers met their program goals during the implementation of the Safe, Accountable, Flexible and Efficient Transportation Equity Act-A Legacy for Users (SAFETEA-LU) using paired sample $t$-tests and time-series with linear trend analysis. The results suggest that mobility indicators better communicate positive outcomes of transit goals within the unique rural transit environment. Using service characteristics data as mobility indicators to supplement the traditional performance reporting may motivate continuous investment in non-urbanized transit programs at different levels government.
\end{abstract}

Keywords: Public transit performance indicators, mobility, efficiency, effectiveness, policy implementation, rural transit environment

\section{Introduction}

Performance evaluation is one of the tools used to substantiate the existence of many public programs. Performance measures are used "to evaluate, control, budget, motivate, promote, celebrate, learn, and improve" (Behn 2003, 586). Thus, organizations must identify the important indicators that work for their specific purposes. In the case of many public and community transit programs, funders-mainly, Federal Transportation Administration (FTA) and state and local governments-dictate indicators of performance. The non-urbanized (rural) area formula, known as FTA's Section 5311 program, is administered through state Departments of Transportation (DOTs) and provides capital and operational funds to support transit programs for 
residents living within census-defined populations of less than 50,000, providing rural residents with vital links to essential places of social and economic importance (KPH and Associates 2009; FTA 2010).

SAFETEA-LU (Safe, Accountable, Flexible and Efficient Transportation Equity Act-A Legacy for Users), which significantly increased both capital and operational funding for 5311 programs by nearly $74 \%$, mandated the non-urbanized programs to report performance data through the National Transit Database (NTD) in 2005 (KPH \& Associates 2009). However, long before this mandate, some DOTs required rural transit sub-recipients to submit quarterly performance data as part of their competitive allocation process following the increased transit funding under the Transportation Equity Act for Twenty-First Century (TEA-21) of 1998. DOTs performance data reporting may have provided the foundation for FTA's renewed requirements under subsequent transit policies (Sen et al. 2012).

Several provisions accompanied SAFETEA-LU's increased funding that provided the framework for transit providers to improve overall performance. For example, the policy afforded the flexibility to use non-DOT federal funds as a local match for FTA programs, to transfer operation equipment among providers, and to purchase and coordinate services. Implementation of such strategies renewed the focus on improving the overall rural transit performance, evidenced by increasing the mobility of transit-dependent individuals as well as efficiency and effectiveness (Burkhardt et al. 2004; Edrington and Brooks 2013; TTI 2012).

Although many studies have concentrated on identifying indicators for assessing the performance of larger urban transit programs, there has been limited focus on finding indicators that are consistent with non-urbanized transit environment. It has been decades since Carter and Lomax (1992) attempted to develop a methodology to evaluate the relative performance of operations of rural transit service funded through the Section 18 Program, finding limitations in comparability among agencies in rural areas that receive similar funding. Since then, some studies have proposed the need for alternative performance indicators for rural systems (see Radow and Winters 1998; Kosky 1999; Sen et al. 2012; Edrington and Brooks 2013). However, there is limited (if any) consistency among propositions, most of which are livability indicators, and many of the indicators are yet to be tested in non-urbanized settings.

In response to the call for diversified performance indicators data across transportation settings (Yusuf and Leavitt 2014), this study attempts to bring to light some of the unique indicators that some DOTs use, with focus on the Mississippi Department of Transportation's (MDOT) Section 5311 program. Non-urbanized transit systems use performance indicators that correspond to their operational goals, which are formulated based on the requirements of funding policies. For example, the goal of FTA Section 5311 funds aims at providing safe and accessible transportation to rural residents connecting to market centers, jobs, hospitals, education, and other essential areas of socio-economic importance (FTA n.d.). Rural transit agencies receiving FTA funding through MDOT set operational goals aimed at increasing ridership related to employment, medical, education, shopping, and others (mobility). In addition, the 
agencies strive to adopt effective strategies to reduce cost (efficiency) and increase trips per service hour and miles covered (effectiveness).

As part of funding requirements, Section 5311 sub-recipients are mostly non-profit agencies and dependent largely on public funds (FTA n.d.). Consequently, all 16 providers included in this study depend on FTA funds administered through MDOT and state and local match funds. Funding consists of a federal/state and local share of $80 \% / 20 \%$ of all project administrative, planning, and capital expenditures, with operating expenditures not exceeding 50\%/50\% of net operating costs (FTA 2010). Thus, it seems apparent that the accomplishment of operational goals is contingent upon the availability of funds. SAFETEA-LU increased rural transit funding by $74 \%$, and the transit agencies could access funds through MDOT along with local funds from state and local governments by justifying the ability to achieve the goals identified above.

This study, therefore, used a synthesis of traditional and non-traditional performance indicators consistent with rural transit goals to verify if the transit agencies collectively met their mobility, efficiency, and effectiveness goals during SAFETEA-LU policy implementation in Mississippi. SAFETEA-LU expired in 2009, and subsequent funding authorized through continuing resolution expired in September 2012. However, the author used SAFETEA-LU policy implementation periods as a reference point for timeseries data analysis to show how FTA Section 5311 programs in Mississippi use mobility data for measuring program outcomes. The study attempted to answer the following questions:

1. Did the selected rural transit agencies meet their goal of increasing the effectiveness of Section 5311 programs during SAFETEA-LU policy implementation?

2. To what extent did Section 5311 transit providers in Mississippi meet their efficiency goals during SAFETEA-LU policy implementation?

3. Did the Section 5311 program meet its mobility goals during SAFETEA-LU implementation in Mississippi?

\section{Conceptual Framework}

The research questions were examined within the conceptual framework summarized in Figure 1. The public rational choice theory extension (Neiman and Stambough 1998) guided this framework. This theory assumes that for any funding policy reauthorization, policy-makers considered the benefits of increasing funds in relation to investment in such programs and, therefore, an increase in funding theoretically should result in increased transit program outcomes. 
FIGURE 1.

Conceptual framework for evaluating MDOT's Section

5311 program outcomes during SAFETEA-LU implementation

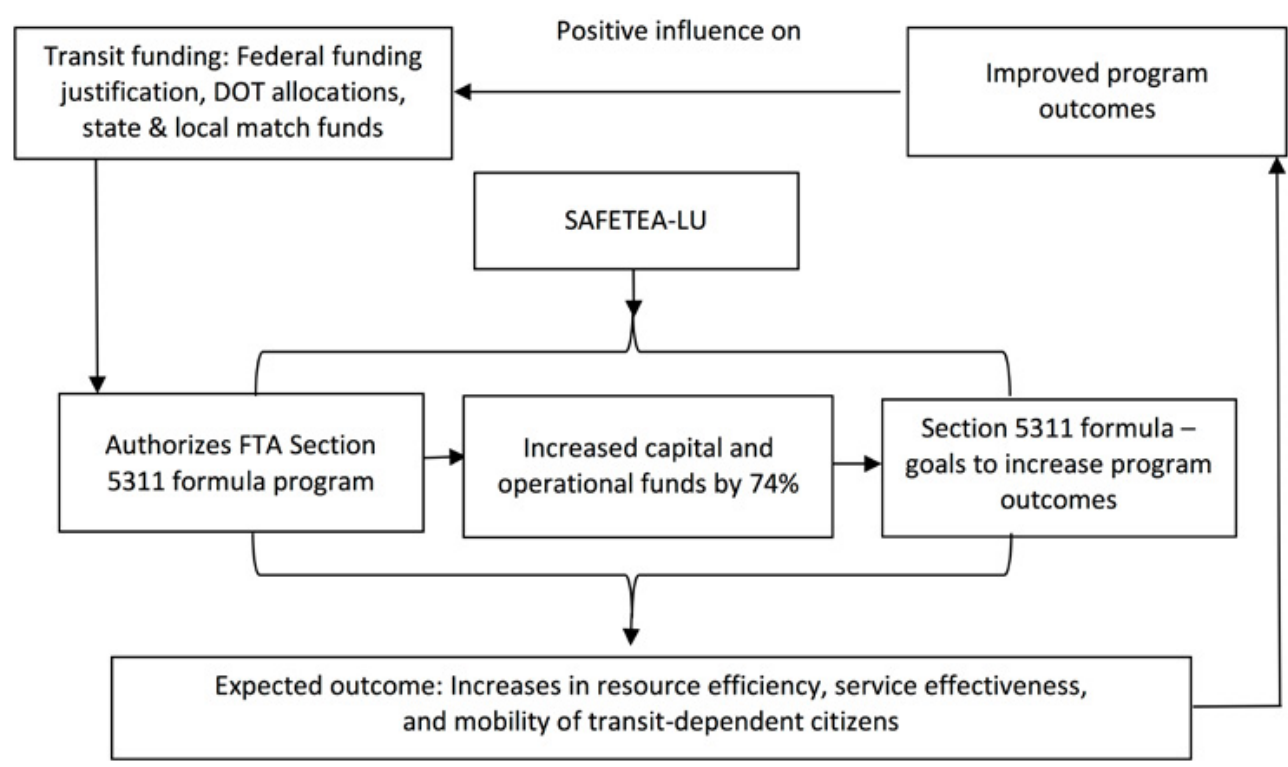

Consequently, the framework was based on the proposition that an increase in transit funding under SAFETEA-LU (capital and operational funds for the Section 5311 programs) along with other policy strategies should assist rural transit providers in reaching their performance goals. Because non-urbanized transit goals are tied mostly to funding objectives and requirements, MDOT's ability to monitor and report performance outcomes could inform funding decisions at the state and local levels. Rural transit agencies, therefore, report program outcomes to inform policy- and decision-makers about transit benefits and effects on communities. Improved outcomes may positively influence transit funding and allocation decisions at the federal, state, and local levels (Figure 1). This study does not intend to make any causal assertions regarding the impact of SAFETEA-LU policy on transit performance outcomes. Rather, it extends the theoretical and practical propositions concerning the use of different performance indicators to evaluate and communicate rural program outcomes, given the funding goals and requirements within the unique rural transit environment.

\section{Related Literature: Performance Measurement and Evaluation in the Transit Industry}

Performance measurement is used not only to identify and remedy problems among employees or to justify budgets and expenditures, but also to measure improvements in performance and document the program impact on the communities (Fielding 1987; FTA 2010). Without proper performance data, transit managers have no yardstick to improve existing services, plan for future services, or justify the continuation of existing services. Performance evaluation also helps to assess the returns on investment to justify government intervention resulting from market failures.

When local governments took over problematic transit operations and federal government subsidies became available, ridership and revenue-used to gauge urban transit performance-no longer were considered adequate measures of performance 
(Winston 2000; Karlaftis 2004). In many cases, evaluation of government-funded programs examines the benefits society may derive or improvement in the quality of life of target populations. Consequently, research and experts suggest that since the outcome of program evaluation may negatively affect the survival of most public programs, it is important to select indicators that are unique to each program rather than use general performance indicators (see Behn 2003; Hatry et al. 2010; Wholey 2010).

Because of the lack of a market-oriented guide to performance measurements, it was hypothesized that a more balanced assessment would help capture the new multidimensional nature of transit operational performance (Carter and Lomax 1992; Karlaftis 2004; Espino et al. 2007). Efficiency and effectiveness constructs became the traditional measures, and researchers have used these indicators widely to examine improvement in urban transit performance and productivity (e.g., Berechman 1993; Karlaftis and McCarthy 2002; Karlaftis 2004). Indicators used with these constructs include revenue passengers per service area population, total passengers per vehicle hour or mile, and revenue per vehicle hour or mile (effectiveness variables) as well as cost per vehicle mile or hour and cost per trip (efficiency variables) (Fielding 1987). However, research has emphasized that efficiency and effectiveness indicators work very well in the urban transit environment and are considered less effective when used alone for evaluating non-urbanized transit performance (Burkhardt et al. 2004; Ellis and KFH Group Inc. 2009).

Based on earlier research, some empirical studies have explored ways of incorporating the unique rural transit environment into the traditional efficiency/effectiveness measurement of performance analysis. Bitzan and Hough (1994) developed a guidebook for evaluating performance in rural and small urban transit systems for the Mountain Plains Region, in which they divided performance measures into efficiency and effectiveness categories. Efficiency categories were cost of operations, labor, administration, revenue, maintenance, and vehicles. Effectiveness categories were social and service utilization. Each category contained general measures that can be used to evaluate the overall system performance (Hough et al. 1997).

By 1998, a few state DOTs had developed performance measures specifically to allocate state transit funds to rural transit programs through a competitive process. For example, MDOT developed performance measurement indicators for assessing productivity, efficiency, and effectiveness similar to the Mountain Plains Region's performance categories (MDOT 1998). In addition, MDOT uses service characteristics (called mobility indicators) as part of its performance indicators.

Other empirical studies on non-urbanized and demand-response transit performance have used efficiency and effectiveness ratios to assess performance and productivity (e.g., Burkhardt et al. 2004; Ellis and KFH Group Inc. 2009). The results of these studies showed that many of these indicators could not adequately inform policy- and decision-makers on goals achievement. Also, there have been questions regarding the comparability of findings across studies, as they yielded conflicting results (Karlaftis 2004). These concerns led to the conclusion that no single indicator or method could 
reveal the relative outcome of transit operations, but a combination of reliable and consistent mix of indicators could (Behn 2003; Hatry et al. 2010; Wholey 2010).

Moreover, studies have found that non-urbanized transit operates in unique environments, such as distinctively large geographic areas with low population densities, lower-income groups, more demand-response services, and distinct categories of transit-dependent groups (Economic Research Service 2005; Radow and Winters 1998). In addition, travel is for longer distances, using resources that often are strained and stretched (Ellis and KFH Group Inc. 2009). Consequently, rural transit programs require varied forms of performance indicators that are consistent with their goals and provide insight into transit benefits to communities (Radow and Winters 1998; Kosky 1999; Burkhardt et al. 2004; Edrington and Brooks 2013). Although some contend that varied forms of indicators could be used to remove any skewed outcomes that may result from the exclusive use of traditional efficiency and effectiveness performance analysis (Radow and Winters 1998), others indicate that different purposes require different measures (Behn 2003).

Other performance categories found in rural transit literature include accessibility, mobility, safety, system preservation, and reliability measures (see Burkhardt et al. 2004; Caltrans 2006). The definitions of mobility measures differ across states. For example, Caltrans identified level of service (LOS) as the primary measure of mobility whereby several counties reported ridership trends without any particular mobility data. However, Caltrans' report proposed automating count data to record critical locations or destinations (Caltrans 2006). In the case of Mississippi and Arkansas, mobility data include the type of destination and trip purpose data, which reveal the impact of the transit services on a community in increasing mobility. These data types are consistent with quality-of-life measures such as the number of passengers transported to meal sites, social and recreational centers, employment, and other socially- and economically-beneficial destinations (Radow and Winters 1998; Kosky 1999).

Researchers from Texas A\&M Transportation Institute recommend the use of alternative indicators in analyzing rural transit and coordinated transit performance (Sen et al. 2012). These indicators help document how the transit system affects business, employment, health care, or other issues important to the community; more importantly, the measures address what would happen if the transit system did not exist (Edrington and Brooks 2013). Such measures also show how the mobility needs of communities are being met through rural transit systems using specific types of service data as indicators of performance outcomes (Sen et al. 2012).

Even though the transit performance literature shows no uniform set of measures for assessing performance, it revealed three macro constructs that have been used in specific settings to evaluate rural transit program outcomes: service effectiveness, resource efficiency, and mobility measures. Service effectiveness, as identified in the literature, assesses the amount of public transportation service consumed (revenue received or passengers trips) per the quantity of service provided. Thus, the more service consumption (or passenger revenue or passenger trips) per service output (vehicle miles and hours), the higher the level of service effectiveness (Burkhardt et al. 2004). 
Resource efficiency, on the other hand, measures the amount of resources expended (operating cost) per unit of rural transit service (vehicle hours or miles and total passenger trips) (Fielding et al. 1985; Karlaftis and McCarthy 2002; Burkhardt et al. 2004). Thus, the smaller the amount of resources expended to produce a unit of service, the greater the resource efficiency of the public transportation service (Burkhardt et al. 2004). These measures are necessary because transit agencies transport clients within the constraints of existing resources, and resource increases, such as SAFETEA-LU funding, should have an effect on program outcomes.

The mobility indicators include those that relate to trip, services, and passenger types (Radow and Winters 1998; Kosky 1999). These trip characteristics indicate how the mobility needs of various categories of rural residents were being met before and after funding increased under SAFETEA-LU implementation. Trip characteristics include employment, medical, education, health and human services (HHS), shopping, and recreational destinations (Radow and Winters 1998).

\section{Methodology}

\section{Variables Included in This Study}

All the three constructs discussed (effectiveness, efficiency, and mobility) consist of many variables for measuring performance outcomes. However, the author selected only those variables that MDOT commonly uses to compare how each construct could better inform funding decision-makers about rural transit program outcomes. Table 1 summarizes the macro constructs and variables within the scope of this case study.

TABLE 1.

Selected Performance Construct for MDOT's Non-Urbanized Transit Performance

\begin{tabular}{|l|l|l|}
\hline \multicolumn{1}{|c|}{$\begin{array}{c}\text { Macro } \\
\text { Indicators }\end{array}$} & \multicolumn{1}{|c|}{$\begin{array}{c}\text { Component of Macro } \\
\text { Construct Being Measured }\end{array}$} & \multicolumn{1}{c|}{ Variable/Measure } \\
\hline $\begin{array}{l}\text { Service } \\
\text { Effectiveness }\end{array}$ & Service utilization & $\begin{array}{l}\text { Passenger trips per hour, and total } \\
\text { revenue per mile }\end{array}$ \\
\hline $\begin{array}{l}\text { Resource } \\
\text { Efficiency }\end{array}$ & Resource utilization & $\begin{array}{l}\text { Operating cost per passenger trips and } \\
\text { cost per vehicle mile }\end{array}$ \\
\hline Mobility & $\begin{array}{l}\text { Mobility of transit-dependent - } \\
\text { using transit to meet mobility } \\
\text { needs, trip/service types }\end{array}$ & $\begin{array}{l}\text { Number of employment-related, medical, } \\
\text { HHS, education/training, and shopping } \\
\text { trips }\end{array}$ \\
\hline
\end{tabular}

Total operating cost is the cost of operating a transit system, including all labor, materials, and services necessary for operations, maintenance, and administration but excluding capital cost (per NTD). Revenue (contract and fare) hours and miles are the hours and miles that vehicles are in passenger service or available (with a driver) for service (per NTD). Passenger or service trips variable, including trip types, as used in this study, is a count of the number of passengers who board the Section 5311-funded vehicle, with passengers counted each time they board a vehicle. 
Mobility indicators include the following:

1. Employment-related trips are trips to and from places of employment, including all trips related to Temporary Assistance for Needy Families (TANF) clients.

2. Medical trips are trips to doctor offices, clinics, and hospitals and all trips for receiving medical services, including Medicaid-sponsored trips.

3. HHS trips are human service agency trips often provided under contract with human service agencies and include trips related to social service functions such as housing, shelter, clothing, Food Stamps, and Medicare assistance.

4. Education/training trips are trips to schools, colleges, and other facilities for the purposes of receiving education and training. These include trips to Head Start programs.

5. Shopping/personal trips are trips to stores, beauty salons, utility companies, post offices, County courthouses, City halls, and other personal trips.

\section{The Case of Mississippi's Rural Transit}

A preliminary exploration of other states' rural transit data identified Mississippi as the only state that provides all conditions necessary for testing the propositions set by the study. MDOT is one of the few state DOTs that continually had collected diversified 5311 performance data before NTD reporting became a mandate under SAFETEA-LU. Hence, the unique type of data collected by MDOT and the use of the data in the competitive allocation process represents a peculiar case for the testing usefulness of diverse performance data in a rural transit environment.

Unlike many state DOTs that allocate funds by some prescribed formulas, MDOT uses a competitive selection process. MDOT and the Interagency Transportation Committee (ITC) select the projects to ensure a feasible resource coordination, utilization, and efficiency across the state (MDOT State Management Plan [SMP] 2011). The process gives priority to existing Section 5311 providers that demonstrate effective coordination of available resources and otherwise have been operating satisfactorily based on the MDOT's monitoring, review, and audit procedures. Providers must have measurable service delivery goals and specific objectives to meet service demands as part of grant allocation rankings (MDOT SMP 2011). Thus, sub-recipients must document changes in specific services provided (mobility variables), efficiency and effectiveness goals, and a possible expansion of service area and marketing efforts over a two-year period (MDOT SMP 2011).

To provide a balanced approach to rural transit performance measurement (Carter and Lomax 1992; Radow and Winters 1999), MDOT combines the traditional efficiency and effectiveness indicators with non-traditional indicators called mobility indicators (which reflect FTA Section 5311 funding policy goals) for monitoring program outcomes. MDOT's Transit Division has received first-hand mandatory quarterly data from subrecipients and maintained detailed operational data since 1999, and MDOT and ITC have used performance data and other service operational criteria to select projects in the competitive grant circles since 2000. In addition, MDOT reports the data to NTD 
under SAFETEA-LU requirements and publishes performance outcomes in an Annual Statewide Coordination Summit book for public consumption. The annual reporting is part of a continuous attempt to educate transportation stakeholders and funding decision-makers at all levels of government about the benefits of transit programs.

\section{Study Design and Data}

This study employed a single evaluative case study design with embedded units of analysis (Yin 2009). Mississippi's Section 5311 program was the case, and the units of analysis constituted 16 rural transit providers receiving Section 5311 grant through MDOT. Using a before-and-after design (Berman 2007; Yin 2009), the study assessed how the Section 5311 program in Mississippi met its program goals during SAFETEA-LU implementation. Data for this study were obtained from MDOT's Automated Transit Data System (ATDS).

Overall, 16 out of 22 (73\%) Section 5311 providers that were in good standing regarding goal setting, FTA funding receipts, and quarterly data reporting were included in the study. The 16 providers satisfied the conditions for pairing the data for conducting a paired sample t-test and time-series analysis. The data collected cover 8 years or 32 quarters (September 2001-October 2009) of Federal Fiscal (FF) years, representing four years before and four years after SAFETEA-LU implementation. In total, 512 datasets were uploaded to SPSS software, which generated 32 sets of time-series data for the statistical analysis. Each quarterly data point represents a quarterly average of data reported.

\section{Methods of Analysis}

SPSS was used to run the paired sample t-test to compare the means of dependent variables (which are related variables) during the pre-policy and policy periods. This type of test assumes that both variables are at interval or ratio levels and were measured with the same scale. In addition, time-series regression with linear trend analysisthe best fit for evaluating outcomes over a period and for the forecasting effect of increased federal funding (Berman 2007) - were used to compare quarterly trends of performance indicators over the pre-policy and policy periods. A trend line equation that linked two variables provided an added explanation of any slight changes observed from one period to the other, thus predicting how one variable will change given any change in other future resources (Berman 2007). The pre-policy and policy periods were the independent variables. Thus, the independent variables were continuous or dichotomous (dummy variables). The dependent variables were continuous, comprising the quarterly operational data (passenger trips per hour, revenue per mile, cost per mile, cost per hour, and trip/service types related to education, employment, HHS, medical, and shopping).

The pre-SAFETEA-LU period covered the data-reporting period of October 2001 through September 2005, and the implementation period covered October 2005 through September 2009. The trend line equations (regression coefficients) were analyzed separately for the two periods without creating any interruptions. The coefficients in each pair were tested and were statistically different from each other. The omitted variables from each period did not make any difference in the overall results. 
Trend lines allowed the researcher to identify changes over the pre-policy and policy periods.

Error terms in time series regression met the same assumptions concerning normalitythe absence of outliers, linearity heteroscedasticity, and multicollinearity. Any identified effects of outliers on regression conclusions were examined by re-estimating averages and then examining conclusions for substantive robustness. Even though caution was taken in comparing performance indicators, there were some variations in passenger data. Unequal variances of the error terms were detected graphically by examination of error term plots for unequal variance, transforming the affected variables, and adjusting the scale to reduce the differences between variables (Stevens 2002; Berman 2007). The independent variables were linearly related to dependent variables and did not exhibit the problem of multicollinearity (Berman 2007).

Autocorrelation reflects correlation in the order in which observations are measured. Durban-Watson test statistics (DWTS) were used to prevent the problem with autocorrelation. The values of DWTS ranged from $0-4$. Values close to 2 indicated a lack of serial correlation, and values close to 0 and 4 indicated serial correlation. Values less than 2 indicated positive serial correlation; values greater than 2 indicated a negative. The DWTS of variables analyzed exhibited the limited presence of autocorrelation. However, the trend variables added to the model helped to control any problem that may exist.

\section{Results}

\section{Effectiveness Construct}

Operational effectiveness did not show any improvement during SAFETEA-LU implementation. The indicators (passenger trips per hour and revenue per mile) decreased during the policy period. The results are summarized in Table 2. The average passenger trips per hour during the policy implementation period were slightly lower $(m=3.36, S E=0.173)$ than the mean during the pre-policy period $(m=4.30, S E=0.126)$ thus, a $22 \%$ decrease in passenger trips per hour during the policy implementation period (see Table 2). The t-test found a significant decrease in passenger trips per hour after SAFETEA-LU implementation $(t(30)=4.408, p<0.01)$. The trend analysis also showed a rapid quarterly decline in the variable during pre-policy and policy implementation periods (see Figure 2).

\begin{tabular}{|c|c|c|c|c|c|c|c|}
\hline \multirow{5}{*}{$\begin{array}{r}\text { TABLE } 2 . \\
\text { Means Test of } \\
\text { Effectiveness Indicators }\end{array}$} & \multicolumn{2}{|c|}{ Indicators } & Means & SE & $\%$ Change & $t$ & Sig. (2-tailed) \\
\hline & \multirow{2}{*}{$\begin{array}{l}\text { Passenger trips } \\
\text { per hour }\end{array}$} & Pre-policy & 4.3004 & 0.12653 & \multirow{2}{*}{-22} & \multirow{2}{*}{$4.408^{* *}$} & \multirow{2}{*}{0.000} \\
\hline & & Policy period & 3.3551 & 0.17312 & & & \\
\hline & \multirow{2}{*}{ Revenue per mile } & Pre-policy & 0.7919 & 0.03844 & \multirow{2}{*}{-50} & \multirow{2}{*}{$8.512^{* *}$} & \multirow{2}{*}{0.000} \\
\hline & & Policy period & 0.3985 & 0.02566 & & & \\
\hline & ${ }^{*} p<0.05$ & ${ }^{* *} p<0.01$ & & & & & \\
\hline
\end{tabular}



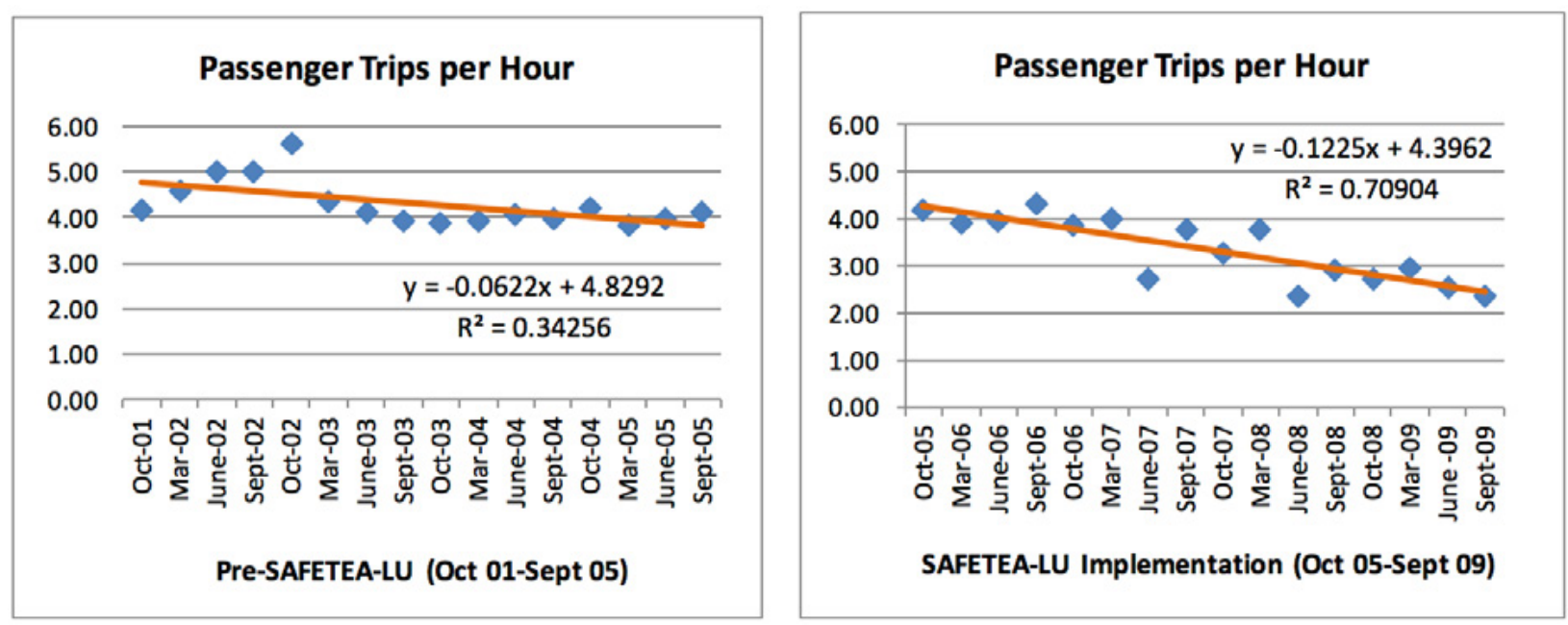

FIGURE 2. Passenger trips per hour trend comparison (quarterly averages), FFY 2001-2009

The revenue per mile recorded during the policy implementation period was much lower $(m=0.3935, S E=0.025)$ than that of the same variable during the pre-policy period $(\mathrm{m}=0.7919, \mathrm{SE}=0.038)$. This represents a $50 \%$ decrease in revenue per mile during the policy implementation period (see Table 2). The t-test (Table 2) confirmed that there was a significant difference $(t(30)=8.512, p<0.01)$. The trend analysis in Figure 3 revealed that the rate of quarterly decline continued during the implementation of SAFETEA-LU period, but at a slower pace.
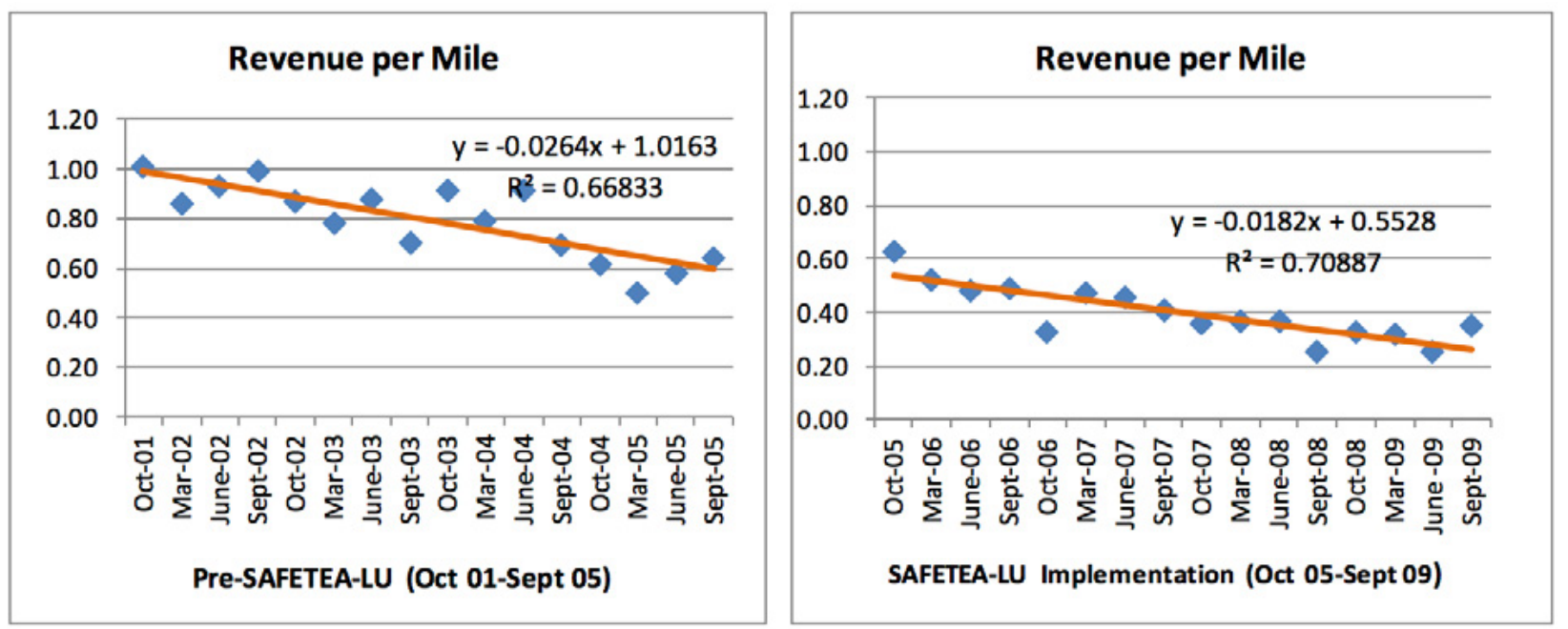

FIGURE 3. Revenue per mile trend comparison (quarterly averages), FFY 2001-2009 


\section{Efficiency Construct}

Resource efficiency indicators did not show any improvement during SAFETEA-LU implementation. Table 3 provides a summary of statistics for both variables. Cost per passenger trip during the policy period was $44 \%$ higher $(m=7.3789, \mathrm{SE}=0.453)$ than that of the pre-policy period $(\mathrm{m}=5.146, \mathrm{SE}=0.162)$, whereas that of cost per mile increased by $9 \%$.

\begin{tabular}{|c|c|c|c|c|c|c|c|}
\hline \multirow{5}{*}{$\begin{array}{r}\text { TABLE } 3 . \\
\text { Means Test of } \\
\text { Efficiency Indicators }\end{array}$} & \multicolumn{2}{|c|}{ Indicators } & Means & SE & $\%$ Change & $\mathbf{t}$ & Sig. (2-tailed) \\
\hline & \multirow{2}{*}{$\begin{array}{l}\text { Cost per } \\
\text { passenger trip }\end{array}$} & Pre-policy & 5.146 & 0.162 & \multirow{2}{*}{$44 \%$} & \multirow{2}{*}{$-4.659 * *$} & \multirow{2}{*}{0.000} \\
\hline & & Policy period & 7.389 & 0.453 & & & \\
\hline & \multirow{2}{*}{ Cost per mile } & Pre-policy & 0.869 & 0.024 & \multirow{2}{*}{$9 \%$} & \multirow{2}{*}{-1.947} & \multirow{2}{*}{0.061} \\
\hline & & Policy period & 0.945 & 0.031 & & & \\
\hline
\end{tabular}

The t-test for cost per passenger trip showed a significant difference $(t(30)=-4.659$, $\mathrm{p}<0.01)$. However, the $t$-test for cost per mile found no significant difference $(t(30)=-$ 1.947, $p>0.05$ ) during the policy implementation period (see Table 3). The quarterly trends in cost per output in both variables (cost per passenger trip and cost per mile) increased dramatically during SAFETEA-LU implementation (see Figure 4).
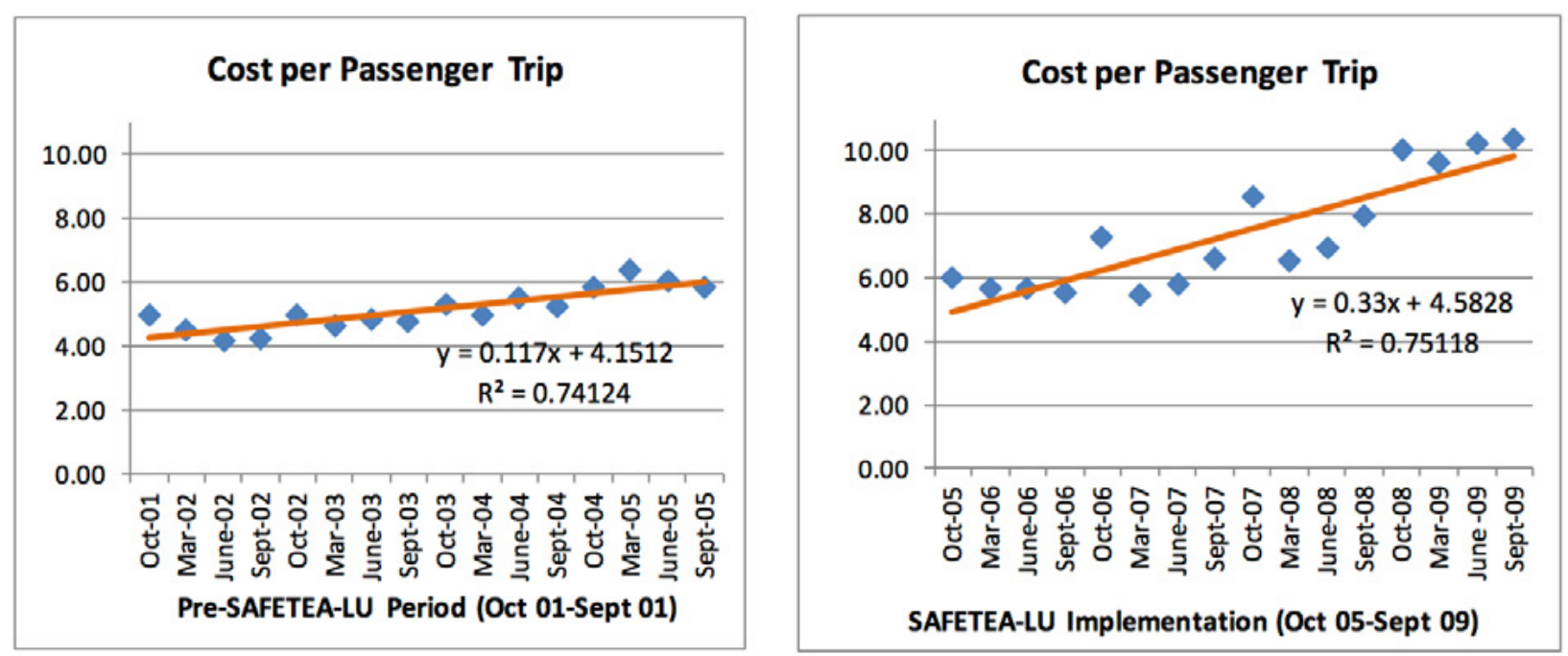

FIGURE 4. Cost per passenger trip trend comparison (quarterly averages), FFY 2001-2009

\section{Mobility Constructs}

The analysis revealed an increase in medical, HHS, and education/training trips during policy implementation. However, employment- and shopping-related trips decreased during the policy implementation period. Table 4 summarizes the statistical analysis. During policy implementation, medical trips for all 16 transit agencies were 363\% higher ( $m=28295, S E=1779)$ than the mean recorded during the pre-policy period $(m=6110, S E=902)$. The $t$-test also found a significant difference $(t(30)=-11.124, p<0.01)$ 
(see Table 4). The trend analysis revealed significant quarterly increases in medical trips during the pre-policy period, which almost doubled during the policy implementation period (see Figure 5). Similarly, HHS trips recorded during the policy implementation period were higher $(m=22647, S E=1125)$ than those of the pre-policy period $(m=11504$, $\mathrm{SE}=697)$. This presents a $97 \%$ increase (11143 more HHS trips) during the SAFETEA-LU implementation period. The $t$-test also found a significant difference $(t(30)=-8.418$, $\mathrm{p}<0.01$ ) in HHS service trips (see Table 4). The quarterly trends also showed continued increases during the pre-policy and policy implementation periods.

\begin{tabular}{|c|c|c|c|c|c|c|c|}
\hline \multirow{13}{*}{$\begin{array}{r}\text { TABLE } 4 . \\
\text { Means Test of Mobility } \\
\text { Indicators (Trip/Service } \\
\text { Characteristics) }\end{array}$} & Indicators & Policy Periods & Mean & $\begin{array}{l}\text { Std. Error } \\
\text { Mean (SE) }\end{array}$ & $\%$ Change & $\mathbf{t}$ & Sig. 2-tailed \\
\hline & \multirow{2}{*}{ Medical } & Pre-policy & 6110.000 & 901.661 & \multirow{2}{*}{$363 \%$} & \multirow{2}{*}{$-11.124^{* *}$} & \multirow{2}{*}{.000} \\
\hline & & Policy Period & 28295.375 & 1778.848 & & & \\
\hline & \multirow{2}{*}{ HHS } & Pre-policy & 11504.375 & 697.495 & \multirow{2}{*}{$97 \%$} & \multirow{2}{*}{$-8.418^{* *}$} & \multirow{2}{*}{.000} \\
\hline & & Policy Period & 22647.375 & 1125.084 & & & \\
\hline & \multirow{2}{*}{$\begin{array}{l}\text { Education \& } \\
\text { training }\end{array}$} & Pre-policy & 13349.813 & 347.546 & \multirow{2}{*}{$25 \%$} & \multirow{2}{*}{$-6.601^{* *}$} & \multirow{2}{*}{.000} \\
\hline & & Policy Period & 16752.563 & 380.764 & & & \\
\hline & \multirow{2}{*}{ Employment } & Pre-policy & 59351.938 & 3220.887 & \multirow{2}{*}{$-41 \%$} & \multirow{2}{*}{$6.953^{* *}$} & \multirow{2}{*}{.000} \\
\hline & & Policy Period & 35052.813 & 1356.222 & & & \\
\hline & \multirow{2}{*}{$\begin{array}{l}\text { Shopping/ } \\
\text { personal/Other }\end{array}$} & Pre-policy & 34658.063 & 1189.914 & \multirow{2}{*}{$-19 \%$} & \multirow{2}{*}{$4.146^{* *}$} & \multirow{2}{*}{.000} \\
\hline & & Policy Period & 28220.563 & 997.397 & & & \\
\hline & \multirow{2}{*}{$\begin{array}{l}\text { Total passenger/ } \\
\text { service trips }\end{array}$} & Pre-policy & 186949.81 & 2698.348 & \multirow{2}{*}{$-3 \%$} & \multirow{2}{*}{1.142} & \multirow{2}{*}{.262} \\
\hline & & Policy period & 182177.81 & 3188.820 & & & \\
\hline
\end{tabular}
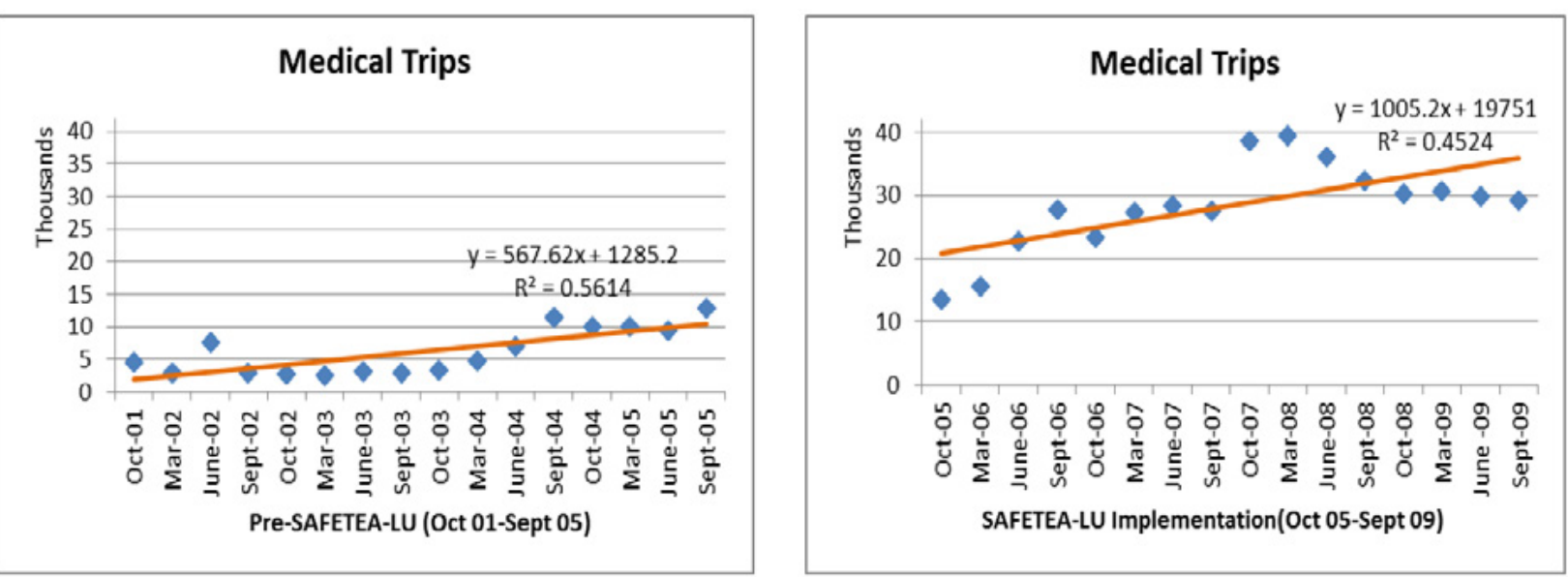

FIGURE 5. 5311 Medical-related trips trends comparison (quarterly averages), FFY 2001-2009 
Education/training trips increased by $25 \%$ ( $m=16753$, SE=381) during the policy implementation period compared to the pre-policy period $(m=13349, \mathrm{SE}=347)$ (see Table 4). The $t$-test also found a significant difference $(t(30)=-6.601, p<0.01)$ in education/training trips during SAFETEA-LU implementation. However, there was a quarterly rate of decline observed in the trend analysis.

On the other hand, the average number of employment-related trips showed a $41 \%$ decline during SAFETEA-LU implementation period, as shown in Table 4. The t-test found a statistically-significant difference $(t(30)=-6.953, p<0.01)$. However, the trend analysis showed that transit providers were losing 2141 employment-related trips quarterly during the pre-SAFETEA-LU period. This decreasing trend seemed to have improved, with a quarterly loss of only 835 trips during SAFETEA-LU implementation period (see Figure 6).
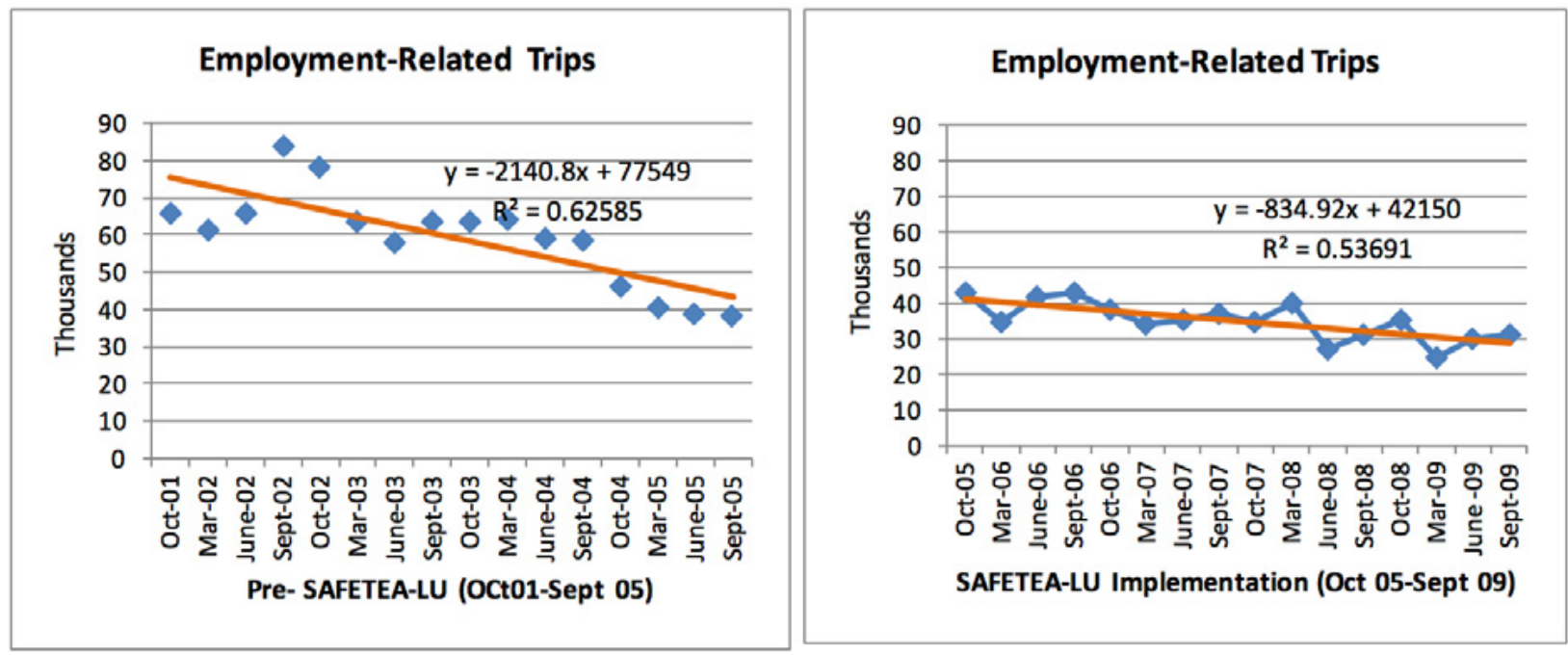

FIGURE 6. 5311 Employment related trips trends comparison (quarterly averages), FFY 2001-2009

Shopping-related trips followed a similar trend as employment trips, with a reduction in the average shopping trips during policy implementation period-thus, $19 \%$ lower $(m=28221, S E=997)$ than that of the pre-policy period $(m=34658, S E=1189)$ (see Table 4). The trend analysis also showed a quarterly loss of 441 shopping trips during the pre- SAFETEA-LU period. This trend, however, slowed down to only 193 quarterly losses during the policy implementation period.

A means test for total passenger trips was calculated to verify the changes in total service trips for 5311 programs during SAFETEA-LU implementation. Total trips during the policy implementation period were slightly lower $(m=182177.81, \mathrm{SE}=3188.820)$ than those of the pre-policy period ( $m=186949.81, \mathrm{SE}=2698.348)$, representing a 3\% decrease in average total passenger trips during the policy implementation period (see Table 4). The $t$-test, however, found no significant difference $(t(30)=1.142, p>0.05)$, as trends in the quarterly loss of total passenger trips also slowed down significantly. 
In summary, effectiveness in terms of passengers per hour and revenue per miles decreased during the policy implementation period, with a slight improvement in quarterly trends in revenue per mile. The efficiency indicators showed a high cost per trip and mile. On the other hand, mobility indicators revealed a significant increase in medical, HHS, education, and training trips. Although total shopping and employmentrelated trips decreased, there was an observed gradual improvement in quarterly losses.

\section{Discussion of Results}

This study focused on exploring diversified indicators for evaluating non-urbanized transit (Section 5311) program outcomes in Mississippi. It followed the proposition that rural transit goals are linked to government funding. Therefore, the increased funding made available under the SAFETEA-LU policy should assist providers in meeting most of their goals of increasing program outcomes. The main outcomes expected of MDOT-supervised rural transit providers include increasing effectiveness, efficiency, and mobility. The before-and-after design was used to examine how the transit agencies included in this study met their goals during SAFETEA-LU implementation in Mississippi. The dynamics of the various indicators provided an explanation of how the agencies achieved their goals during the study period. A mix of traditional service effectiveness and resource efficiency indicators and non-traditional mobility indicators were tested.

The results of the paired t-test and the trend analysis showed no significant indication that rural transit agencies met their efficiency and effectiveness goals. In analyzing effectiveness, it was expected that the more service consumption (passenger trips or revenue) per service output (miles or hours), the higher the level of service effectiveness (Burkhardt et al 2004; Ellis and KFH 2009). The results revealed a reduction in trips per hour and revenue per miles during the policy period. However, the rate of quarterly decline in revenue per mile appears to be slowing down. If this trend continues, then it could be predicted that a continuous increase in funding may eventually improve revenue per mile. In the case of resource efficiency analysis, the expected outcome was an improvement in resource efficiency, as evidenced by a reduction in cost per trip and cost per mile (Burkhardt et al. 2004) during the implementation of SAFETEA-LU. This measure is an important variable for analyzing goal achievement because transit agencies transport clients within the constraints of existing resources and, therefore, resource increases should have an impact on performance service outcomes (Radow and Winters 1999). However, the results of the analysis proved otherwise, showing a high cost per trip and mile during SAFETEA-LU implementation. This trend may be due to the increased funds made available under SAFETEA-LU policy. The increased cost proportions may have translated only to improvement in some mobility indicators. The results of the efficiency and effectiveness indicators were consistent with other studies on transit performance hypothesis, which indicates that these traditional indicators may show no improvement in rural transit performance (Burkhardt et al. 2004) due to the unique rural transit environment (Radow and Winters 1999).

On the other hand, the analysis of mobility indicators revealed that the selected transit providers in Mississippi met some of their mobility goals during SAFETEA-LU 
implementation. The types of services provided to clients represented how the mobility needs of some rural transit-dependent persons improved during the SAFETEA-LU policy implementation period. There was a significant increase in medical and HHS trips and a slight improvement in education- and training-related trips. Even though there was a decrease in employment- and shopping-related trips, the trend analysis revealed that the declining quarterly trends observed before SAFETEA-LU implementation was improving gradually.

The decrease in employment- and shopping-related trips was significant from 20072009, which may be explained by three conditions. First, it could be attributed to the introduction of Job Access and Reverse Commute (JARC) services in some areas, which were not included in this study. Second, other providers that started services after SAFETEA-LU implementation were not included in this study. Third, since employment trips were their lowest between 2007 and 2009, it could be attributed to job losses during the economic recession. The recession reached its highest peak in 2008 (Wall Street Journal 2008) and may have affected shopping trips with the reduction in purchasing power. If the trend observed in the analysis continues, then employment and shopping trips are likely to improve as conditions improve and resources increase with time.

\section{Implications for Policy and Practice}

This study has shed light on how the three diverse performance constructs behave in non-urbanized transit performance evaluation. Although all the indicators matched specific goals typically set by transit providers, only mobility indicators exhibited some positive goal achievement during the implementation of SAFETEA-LU in Mississippi. Consequently, if only the traditional efficiency and effectiveness variables were used in Mississippi's Section 5311 allocation decisions, the ITC, for instance, would not select any of the transit providers included in this study mainly because none of the traditional variables showed any positive improvement. This study, therefore, informs funding decisions and performance reporting policies and practices in many ways.

First, the improvement observed in some mobility outcomes in this study may imply that more services were available to users accessing medical, HHS, and education/ training services during SAFETEA-LU implementation. This outcome could mean enhancement in the quality of life of transit-dependent persons (Kosky 1999; Edrington and Brooks 2013). In Mississippi, such outcomes inspire funding decisions at the state and local levels (MDOT Summit Report 2013). Thus, adding mobility measures to the traditional performance indicators provides the balance needed for rural performance outcomes (Carter and Lomax 1992; Espino et al. 2007) and allows policy-making and funding decision-makers to appreciate rural transit programs and their impact on persons who depend on them.

Second, since mobility indicators define specific services provided, including such indicators in diversified performance measures could be an effective benchmarking and marketing tool for transit providers to get service contracts within municipalities. Consistent with Radow and Winters (1998), identifying specific indicators allows MDOT 
rural transit providers to tell their story and market their programs to specific targets such as hospitals, education institutions, and employment agencies. These targeted measures allow for comparison and consistency of monitoring trends among providers and provide a common measure for examining the socio-economic impact of transit services and returns on public investments. Not only could such data be harmonized, it also could be humanized through practical results sharing.

Third, the results of such analysis may influence funding directions in non-urbanized settings. The gradual improvements in performance trends, as observed in some of the variables, may imply that program requires time to improve after funds have become available. Thus, there is a possibility of increasing program outcomes if policy-makers approve continuous funding of rural transit programs.

Furthermore, since the introduction of formula programs, rural transit agencies in states such as Mississippi have had to convince state and local authorities about transit program benefits to obtain match funds (RTAP and CTAA 2008; Radow and Winters 1999). Thus, transit agencies should use those indicators that can best inform local and state funding authorities and stakeholders. By adding mobility indicators identified in this case study to the traditional efficiency and effectiveness measures, Mississippi transit providers could communicate some positive program outcomes to funding decision-makers at the state and local levels.

Moreover, under the current federal transportation legislation (MAP-21, Moving Ahead in the 21st (entury) and subsequent policies, there has been a continuous emphasis on performance measurement whereby transit funding will be based on performance outcomes. Such policy direction requires government-funded non-urbanized transit agencies to adopt effective performance measures. Since most rural transit program outcomes are dependent on government funding, it is essential that performance reporting measures be formulated to capture variables that are adaptable to all rural transit programs' needs (Radow and Winters 1998; Kosky 1999; Sen et al. 2012; Edrington and Brooks 2013). MDOT's type of mobility variables, as used in this case study, may provide this opportunity. Adding mobility indicators to the traditional NTD reporting could provide a better understanding of transit performance outcomes for national policy decision-making. Such indicators may feed directly into FTA goals for Section 5311 programs and enhance FTA performance reports to justify budgets, continuous funding, and policy decisions at the federal level.

\section{Conclusion}

This case study adds to the contemporary discussion on using adaptable indicators such as MDOT's mobility indicators to supplement the traditional rural performance reporting. The results of the analysis revealed that some mobility indicators showed positive outcomes compared to the traditional efficiency and effectiveness indicators included in this study. Although there is nothing revolutionary about transit performance measures, the use of a mobility construct as identified in Mississippi's case study better communicates non-urbanized transit program outcomes. Consistent with rural transit literature, adding mobility indicators as part of overall performance 
measurement may serve as useful benchmarks, particularly when evaluating funding policy impact at the state level (Loitine and Lawrence 1988). The use of mobility as part of diversified transit performance measures may enable transit stakeholders to appreciate the benefits of rural transit programs in their communities and stimulate support and investment in non-urbanized transit programs.

\section{Limitations and Prospects for Future Research}

As with any social research, this paper has some limitations that also offer opportunities for future studies. First, because of the diverse nature of Mississippi's rural communities, many factors may influence operational performance; the socio-economic, political, geographic, and capital investments and other influences on transit data may vary considerably among providers and their data reporting. The study did not control for such factors because such data were not available. Therefore, the results will be generalizable to providers in localities that shares similar characteristics with the Mississippi's transit environment.

Second, to satisfy data pairing requirements of the paired sample t-test analysis, the study did not include providers that did not have matching data for both pre-policy and policy periods. Thus, the study used 8 years or 32 quarters or periods in a paired sample t-test and time series linear trend analysis. Even though the literature supports the use of such data points in a single evaluative case study (Yin 2009; Berman 2007), a small sample may limit the statistical power of the test. However, significant effects were found, suggesting enough power that justifies the test (Cohen 1992; Stevens 2002). Future research may capture all providers when assessing overall transit performance.

A prospective study also may examine the achievement of other FTA formula program goals to include MAP-21 or future policy time frames, if paired data are available, to increase the data points. Another study may extend this study by testing whether the improving trends observed in some variables actually improved the outcomes over time. Moreover, this case study offers the opportunity for research and practice in identifying and adopting non-traditional mobility indicators that are consistent across different levels of spatial relations (local, regional, state) for evaluating rural transit program outcomes.

\section{Acknowledgments}

The author is extremely thankful to Charles Carr, Director of Intermodal Planning at MDOT and Dr. Johnny B. Gilleylen of Jackson State University for their professional input. Appreciation also is extended for the assistance provided by Shirley Wilson, Zenotha Robinson, and other staff of MDOT's Transit Division in the data collection process. 


\section{References}

Behn, R. D. 2003. “Why Measure Performance? Different Purposes Require Different Measures." Public Administration Review, 63(5): 586-606.

Berechman, J. 1993. Public Transit Economics and Deregulation Policy. BV, Amsterdam: Elsevier Science Publishers.

Berman, E. M. 2007. Essential Statistics for Public Managers and Policy Analysts. 2nd ed. Washington, DC: CQ Press.

Bitzan, J., and J. Hough. 1994. An Evaluation Guidebook for Rural and Small Urban Transportation Systems in the Mountain-Plains Region. Fargo, ND: Upper Great Plains Transportation, Institute North Dakota State University, J1PC Report No. 94-36.

Burkhardt, J. E., C. A. Nelson., G. Murray, and D. Koffman. 2004. Toolkit for Rural Community Coordinated Transportation Services. Transit Cooperative Research Program (TCRP) Report 101.

Caltrans. 2006. Performance Measures for Rural Transportation Systems: A Technical Supplement, a Guidebook. California: Caltrans.

Carter, D. N., and T. J. Lomax. 1992. "Development and Application of Performance Measures for Rural Public Transportation Operators." Transportation Research Record, 1338.

Cohen, J. 1992. “The Power Primer." Psychological Bulletin, 112(1): 155-159

Economic Research Service (ERS). 2005. "Rural Transportation at a Glance." Washington DC: U.S. Department of Agriculture (USDA), Agriculture Information Bulletin, 795.

Edrington, S., and J. P. Brooks. 2013. "Connection between Rural Transit and Rural Livability." Paper presented at 92nd TRB Annual Meeting, January 12-16.

Ellis, E., and KFH Group Inc. 2009 Guidebook for Rural Demand-Response Transportation: Measuring, Assessing, and Improving Performance, TCRP Report 136.

Espino, R, J. de Dios Ortúzar, and C. Román. 2007 "Understanding Suburban Travel Demand: Flexible Modeling with Revealed and Stated Choice Data." Transportation Research Part A: Policy and Practice, 41(10): 899-912.

Fielding, G. J. 1987. Managing Transit Strategically. San Fransisco, CA: Jossey-Bass Publishers.

Fielding, G. J., T. T. Babitsky, and M. E. Brenner. 1985. "Performance Evaluation for Bus Transit." Transportation Research Part A: General, 19(1): 73-82.

Federal Transit Administration (FTA) 2010. "Performance Based Management Agenda, Issued as Part of Overall Federal Highway Administration's National Performance Agenda.: Compendium of Papers, Transportation Research Board, January 2010.

FTA, n.d. "Formula Grants for Other than Urbanized Areas (5311)." http://www.fta.dot. gov/grants/13093_3555.html. Accessed June 2014. 
Hatry, H. P., J. S. Wholey, and K. E. Newcomer. 2010 "Evaluation Challenges, Issues, and Trends." In Handbook of Practical Program Evaluation, Wholey J. S, H. P. Harry, and K. E. Newcomer (eds). San Francisco: Jossey Bass.

Hough, J., A., D. Tolliver, and J. Bitzan, 1997. “Performance of Coordinated and NonCoordinated Rural Transit Systems in the Mountain-Plains Region." Fargo, ND: Mountain-Plains Consortium, Series MPC Report.

Karlaftis, M. G., and P. McCarthy. 2002 "Cost Structures of Public Transit Systems: A Panel Data Analysis." Transportation Research Part E: Logistics and Transportation Review 38(1): 1-18.

Karlaftis, M. G. 2004 "A DEA Approach for Evaluating the Efficiency and Effectiveness of Urban Transit Systems. "European Journal of Operational Research, 152: 354-364

Kosky, S. 1999. "Performance Evaluation for Rural Transit Systems." RTAP National Transit Resource Center.

KPH and Associates. 2009. Rural Transit Achievements: Assessing the Outcomes of Increased Funding for Rural Passenger Services under SAFETEA-LU. TCRP Project J-6, Task 71.

Liotine, M., and K. D. Lawrence. 1988. "An Analytical Investigation of Policy Effects on Transit System Performance Measurement." Socio-Economic Planning Sciences, 22(4): 185-193.

Mississippi Department of Transportation (MDOT). 1998. "A Look at Performance Evaluation and Cost Allocation in Public Transit." http://mdot.ms.gov/portal/ Public_Transit.aspx.

MDOT State Management Plan. 2011. http://mdot.ms.gov/portal/Public_Transit.aspx.

MDOT. n.d. Transit Summit Report, Survival Strategies. http://mdot.ms.gov/portal/ Public_Transit.aspx.

National Rural Transit Assistance Program (RTAP) and Community Transportation Association of America (CTAA). 2008. "Status of Rural Transit."

Neiman, M., and S. Stambough. 1998. "Rational Choice Theory and the Evaluation of Public Policy." Policy Studies Journal, 26: 449-65.

Radow, L., and C. Winters. 1999. "Rural Transit Performance Measures." Technical Assistance Brief \#5, RTAP National Transit Resource Center. www.ctaa.org/.../Rural_ Transit_Performance_Measurement.pdf.

SAFETEA-LU (Safe, Accountable, Flexible and Efficient Transportation Equity Act-A Legacy for Users), 2005, https://www.fhwa.dot.gov/safetealu/summary.htm,

Sen, L., S. R. Majumdar, M. Highsmith, L. Cherrington, and C. Weatherby. 2012. "Performance Measures for Public Transit Mobility Management." Compendium of Papers, Transportation Research Board.

Stevens, J. P. 2002. Applied Multivariate Statistics for the Social Sciences Mahwah, NJ: Lawrence Erlbaum. 
Wall Street Journal. 2008. "Labor Model Predicts Lower Recession Odds." January 28. http://blogs.wsj.com/economics/2008/01/28/labor-model-predicts-lower-recessionodds/.

Winston, C. 2000 "Government Failure in Urban Transportation." Fiscal Studies, 21(4): 403-425.

Wholey, J. S. 2010. "Use of Evaluation in Government: The Politics of Evaluation." In Wholey J. S., H. P. Hatry, and K. E. Newcomer (eds), Handbook of Practical Program Evaluation. San Francisco: Jossey Bass.

Yin, R. K. 2009. Case Study Research: Design and Methods, Vol. 5, 4th ed., Applied Social Science Research Methods Series. London: Sage.

\section{About the Author}

EUNice V. Акото (akotov@hsu.edu) is an Assistant Professor of Public Management at Henderson State University, Arkansas and a co-owner of EDVACO Consulting LLC, a DBE/MBE-certified transit management company. She received her Ph.D. in Public Administration from Jackson State University, a master's degree from The University of Manchester, England, and a B.Ed. from the University of Education of Winneba, Ghana, West Africa. Her experience in transportation spans across her time as a former Eisenhower Transportation Fellow, work with the MDOT's Public Transit Division, serving on TRB's committee on Transit Management and Performance, and consulting with many rural transit agencies. Her research interests include economic and policy impact analysis, transit, and performance management in non-profit and public organizations. 